DOI 10.37882/2223-2982.2021.04-2.22

\title{
ДИСТАНЦИОННОЕ ОБУЧЕНИЕ В КИТАЙСКИХ ВУЗАХ В ПЕРИОД ЭПИДЕМИИ КОРОНАВИРУСА: ОПЫТ, ПРОБЛЕМЫ И РЕШЕНИЯ
}

\section{DISTANCE EDUCATION IN CHINESE UNIVERSITIES DURING THE EPIDEMIC PERIOD: EXPERIENCE, PROBLEMS AND SOLUTIONS}

Mu Azhen

Summary: In order to cope with the sudden outbreak of COVID-19 and to protect the life and health of teachers and students, the Ministry of Education of the People's Republic of China requires that in the spring semester of 2020 all national universities switch to distance education instead of offline teaching. This is the first time that China has implemented full online education across the country. Judging by the results, the event can be considered a success. However, apart from the experience that we have accumulated, there still exist some problems. This article is intended to study the experience and tackle the problems of China's implementation of distance education during the pandemic, in the hope of providing constructive suggestions on distance education for other countries in the world.

Keywords: distance education, COVID-19, China.
$\mathrm{B}$ конце 2019 года в Китае произошла вспышка коронавируса COVID-19, который бушевал повсеместно весной 2020 года. Чтобы остановить распространение эпидемии в переделах кампусов, обеспечить жизнь и здоровье учителей и учеников, в феврале 2020 года Министерством образования Китая было выпущено уведомление с просьбой "школам всей страны отложить начало весеннего семестра 2020 года, учащимся оставаться дома и не выходить на улицу, не устраивать собраний, не проводить и не участвовать в массовых мероприятиях".[1, с.1] В то же время Минобразование Китая для колледжей и университетов специально издало “Советы по организации и управлению дистанционным обучением в колледжах и вузах", в которых было четко отмечено: “Правительство и вузы должны сотрудничать, для того чтобы вместе обеспечить успешный переход колледжей и вузов на дистанционное обучение во время профилактики эпидемии и борьбы с ней, а также для достижения общей цели - "отмена занятий, не означает отмену обучения".[2] Таким образом, на фоне эпидемии дистанционное обучение в вузах Китая незамедлительно трансформировалось из вспомогательного метода в основной метод обучения.

По приказу Минобразования Китая почти все ки-
Му Ачжэнь

к.филол.н., старший преподаватель, Шанхайский политико-юридический университета, Шанхай, Китай 944530282@qq.com

Аннотация: Для того, чтобы противостоять внезапной вспышке COVID-19, защитить жизни и здоровье преподавателей и студентов, Минобразование КНР выпустило приказ о том, что с началом весеннего семестра 2020 года все университеты страны будут переведены с офлайн на дистанционное обучение. Опираясь на полученные результаты, автор делает вывод, что данная инициатива может считаться успешной. Однако в ее рамках не только получено не мало бесценного опыта, но и выявлены существенные проблемы. В данной статье рассматриваются опыт и проблемы, с которыми столкнулись китайские университеты во время внедрения дистанционного образования в период пандемии, а также выдвигаются предложения по их решению, с целью предоставить справочные материалы для успешного внедрения дистанционного образования в других странах мира.

Ключевые слова: дистанционное обучение, коронавирус, Китай.

тайские вузы начали пробный период дистанционного образования. По официальной статистике, до 8 мая 2020 года 1454 университета по всей стране перешли на дистанционное обучение, 1,03 миллиона преподавателей провели 1,07 миллиона онлайн-курсов, в общей сложности - 12,26 миллиона курсов. В программе дистанционного обучения приняли участие 17,75 миллиона студентов.[3] Это первый масштабный опыт проведения онлайн-занятий в китайских вузах. В целом, мероприятие можно считать успешным, в его рамках не только накопилось не мало опыта, но и также обозначились некоторые проблемы.

\section{1.Опыт Аистаншионного обучения Китая во время коронавируса}

\section{1 Разнообразие открытых он^айн-курсов}

"Лучшие открытые курсы являются предпосылкой прочного внедрения дистанционного образования."[4, с. 22] В начале эпидемии Минобразования Китая сформировало 37 высококачественных и технически продвинутых платформ для проведения онлайн обучения, которые не только бесплатно предоставили доступ студентам к более 41000 лучшим открытым онлайн-лекци- 
ям, виртуально-симуляционным занятиям и т.д., но и также подготовили для них 5000 общедоступных массовых онлайн-курсов (далее МООС) во время вспышки коронавируса. Кроме того, к участию в этом масштабном дистанционном обучении было привлечено более 100 социальных и университетских онлайн-порталов. Благодаря созданию высококачественных Интернет-курсов, разнообразные образовательные платформы гарантировали успешное развитие такого грандиозного проекта по обучению «на дому». Среди них наиболее выделяются:

\begin{tabular}{|c|c|c|}
\hline $\begin{array}{l}\text { Китайские вузы } \\
\text { (М00С) }\end{array}$ & 中国大学MOOC & $\begin{array}{l}\text { Китайские вузы (МО0С) бесплат- } \\
\text { но открыли более } 8000 \text { высоко- } \\
\text { качественных онлайн-курсов, } \\
\text { охватывающих } 12 \text { дисциплин } \\
\text { всех специальностей бакалав- } \\
\text { риата. }\end{array}$ \\
\hline Wisdom Tree & !!!!!! 玿韩树 & $\begin{array}{l}\text { Это глобальная крупномасштаб- } \\
\text { ная платформа для кредитных } \\
\text { курсов. Было организовано } 3223 \\
\text { подобных курса для набора } \\
\text { учебных баллов, охватывающих } \\
92 \text { специальности и бесплатно } \\
\text { доступных для всех студентов. }\end{array}$ \\
\hline School online & 响学堂在线 & $\begin{array}{l}\text { Этот портал МООС создан при со- } \\
\text { трудничестве Минобразования } \\
\text { КНР и самого знаменитого ки- } \\
\text { тайского университета Цинхуа. } \\
\text { Организовано } 3464 \text { М00С, госу- } \\
\text { дарственных и провинциальных } \\
\text { "золотых курсов", из которых } \\
\text { выбрано } 1018 \text { МоОС для набора } \\
\text { баллов по кредитным дисци- } \\
\text { плинам. }\end{array}$ \\
\hline Super star Panya & 4 & 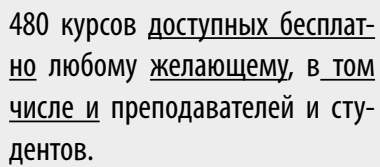 \\
\hline
\end{tabular}

\section{2 Различные интерактивные онлайн-п^атформы}

Кроме вышеупомянутых обучающих платформ, также существуют различные интерактивные платформы для веб-трансляций и интерактивного программного обучения, среди которых наиболее часто используемыми являются Tencent classroom, Tencent conference, $\mathrm{QQ}$, WeChat, ZOOM, Ding-talk. Эти платформы имеют много полезных функций, с помощью которых преподаватель и ученики могут выполнить ряд простых действий таких, как транслировать изображение с экрана монитора, поднять руку, задать вопросы и устроить обсуждение, загрузить информацию. Это должно помочь создать мотивирующую обстановку в классе, повысить энтузиазм учащихся к обучению и учителей к контролю над всем классом.

\section{3 Передовые коммуникационные технологии}

В настоящее время в Китае достаточно развиты коммуникационные технологии. В 2020 году общее число пользователей мобильных сетей China Telecom, China Unicom и China Mobile составило 1,594 млрд семей, коэффициент проникновения - 113,9 ед./100 чел. Среди них число пользователей 4G достигло 1,289 миллиарда семей, что составило 80,8\% от общего числа пользователей мобильных сетей. Смартфоны в Китае уже довольно давно стало обычным явлением, особенно среди студентов. Почти у каждого из них есть личный смартфон. Так что, с точки зрения удобства дистанционное образование больше не является проблемой.

Кроме того, уровень потребления мобильного интернет-трафика продолжает стремительно расти. В 2020 году он достиг 165,6 млрд ГБ, увеличившись на 35,7\% по сравнению с предыдущим годом. Среднемесячный трафик мобильного интернета (DOU) за год достиг 10,35 ГБ/семья॰месяц, увеличившись на $32 \%$ по сравнению с предыдущим годом. DOU в декабре достиг 11,92 ГБ на семью. Это с учетом мобильного интернет-трафика, который составил 156,8 млрд ГБ, что на 29,6\% больше по сравнению с предыдущим годом и составляет $94,7 \%$ от общего объема трафика.

Скорость интернета тоже постоянно растет. К концу 2020 года общее число пользователей фиксированного широкополосного доступа в Интернет в Китае достигло 484 миллионов семей, что, в свою очередь, означает чистый прирост в 34,27 миллиона за год. В то же время, число юзеров высокоскоростного Интернета (100 Мбит/с и выше) составило 435 миллионов, что является 89,9\% от общего числа; обладателями Интернета со скоростью 1000 Мбит/с стали 6,4 миллиона семей. Общее число пользователей в сельских районах страны превысило 140 миллионов, то есть их количество выросло на 7,12 миллиона за год. Таким образом, пользовательский рост в сельских районах и городах достиг одного и того же уровня. К тому же, в Китае в коммерческую эксплуатацию была введена сеть 5G, скорость которой в 20 раз больше, чем 4G. В 2020 году в стране появилось более 600000 новых базовых станций 5G. K настоящему моменту в целом построено более 718000 сооружений данного типа, что позволяет сети охватить все города выше уровня префектуры, а также ключевые округа и более мелкие города по всей стране. [5]

Одним словом, популярность мобильных телефонов и высокоскоростных сетей создали идеальные условия для обеспечения мощным оборудованием и технической поддержки дистанционного образования в период эпидемии коронавируса. 


\section{4 Предварительная информационно- технологическая подготовка преподавателей и студентов}

До эпидемии дистанционное образование рассматривалось преподавателями и студентами, как дополнительное учебное средство, но из-за внезапной вспышки эпидемии стало необходимым полностью изменить способ обучения и в короткое время принять почти новую образовательную модель. Это стало сложной и необычной задачей. Для того чтобы разрешить эту проблему, Минобразование КНР и университеты специально для студентов и преподавателей открыли информационно-технологические онлайн-курсы. Многие образовательные платформы также предоставляют бесплатные ресурсы для подготовки к онлайн-обучению. Например, платформа "Китайские университеты" заранее создала специальные курсы для повышения уровня педагогических теорий и способностей преподавателей пользоваться новейшими информационными технологиями; платформа "School online" начала проводить бесплатные ежедневные онлайн-трансляции для помощи учителям с 30 января 2020 года. "Wisdom Tree” также сформировал, в общей сложности, 28 курсов, для того чтобы научить преподавателей пользоваться их платформой и транслировать занятия.

Данные подготовительные меры значительно повысили уровень способностей учителей и учащихся в использовании информационных технологий и обеспечили успешное начало масштабного дистанционного образования.

\section{2. Проблемы Аистаншионного обучения Китая на фоне коронавируса}

Из-за внезапной вспышки коронавируса в Китае образовательным учреждениям в короткое время пришлось перейти на дистанционное обучение, поэтому не удивительно, что в процессе его внедрения возникло немало проблем.

\section{1 Проблема с сетью}

В целом, в Китае хорошо развита коммуникационная сеть, но существуют заметные различия в отдельных регионах, особенно между развитыми городами и бедными отдаленными горными районами. “Из-за небольшого населения и неудобного транспорта, коммуникационных баз в этих районах относительно мало, коммуникационный сигнал неустойчив и слаб, а также часто подвержен влиянию снега и других аномальных погодных условий." $[6$, с.2] К тому же, большинство семей из этих районов не имеют домашнего широкополосного доступа в Интернет. Для того чтобы участвовать в дистанционном обучении, студентам, проживающих в данной местности, при- ходится использовать мобильный трафик, что создает тяжелую экономическую и психологическую нагрузку.

Кроме того, в основном, платформы для онлайн-обучения отличаются большой пропускной способностью, но избыточный трафик может вызвать перегрузку на платформе. Например, в первый день дистанционных занятий 2020 года почти на всех обучающих сайтах Китая, особенно ведущих, были отмечены серьезные перегрузки сети, зависание изображений и аудио и т.д. Даже появилось шутливое выражение, описывающие данное явление - "большая авария" (имеется ввиду, огромная «пробка», образовавшаяся в Интернете).

\section{2 Проблема с учебными ресурсами}

Во-первых, несмотря на то, что существует общий объем онлайн-курсов, распределение курсов по дисциплинам все еще неравномерно. Это касается в первую очередь спортивных, танцевальных и других практических курсов, которые просто отсутствуют. Во-вторых, "качество онлайн-занятий также неоднородно" [7, с.15]. Одновременно с этим необходимо учесть, что содержание МООС фиксировано. Это создает трудности учета специфических различий студентов, таких, как их региональных различий, способностей, характера, интересов и т.д. Одним словом, трудно персонализировать обучение в зависимости от индивидуальных особенностей учеников.

\section{3 ТруАности, с которыми столкнулись преподаватели и студенты}

Прежде всего, до начала дистанционного обучения преподавателям пришлось не только выбрать наиболее высококачественные онлайн-курсы из множества вариантов, но и овладеть техникой создания онлайн-презентаций, записи видео, пользования обучающих порталов, управления программным обеспечением и другими навыками. Это потребовало у преподавателей большой затраты времени и усилий по сравнению с традиционным обучением. Кроме того, не все преподаватели отличаются высокой информационной грамотностью. У некоторых, особенно пожилых преподавателей, способность к дистанционному обучению ограничена, что приводит к неудовлетворительным педагогическим результатам такого образования. Большие онлайн-группы затрудняют установления порядка в классе, особенно на занятиях по языковой практике.

Что касается студентов, им также необходимо время, чтобы привыкнуть к внезапному переходу на полное обучение на дому. Долго находясь перед монитором компьютера, они быстро начинают чувствовать усталость глаз и тела, а также снижение концентрации внимания. Без взаимодействия тет-а-тет мотивация и активность 
студентов в классе снижаются, притом их способность оставаться сфокусированными ослабевает. В некоторых более серьёзных случаях это даже может вызвать отвращение к учёбе.

\section{3. Совершенствование Аистаншионного образования в Китае}

\section{1 Расширение доступа в Интернет}

Для того чтобы преодолеть трудности доступа студентов в Интернет в бедных и отдаленных районах, местные органы власти должны активно сотрудничать с университетами для улучшения сетевой коммуникационной среды на местах, а также предоставить определенные политические льготы и экономическую помощь учащимся из малоимущих семей для участия в онлайнобучении.

\section{2 Отбор образовательных п^атформ}

Преподаватели должны выбрать подходящие образовательные платформы в соответствии с характеристиками предметов и курсов, иногда даже прибегнуть к использованию такой двойной модели, как образовательные порталы + интерактивные платформы. Например, Super star Panya+WeChat; Wisdom Tree+Tencent conference; School online+QQ live...Преподаватели могут свободно комбинировать различные платформы в зависимости от учебного плана и реальной ситуации. Сочетание двух способов обучения гарантирует двойную надежность. Этот метод не только может перенести процесс преподавания и интерактивную деятельность на две не зависимые друг от друга платформы, но и эффективно снизить нагрузку на какую-либо из них. Итак, необходимо использовать взаимодополняющие преимущества онлайн-ресурсов для увеличения активности учащихся.

\section{3 Оптимизачия он^айн-курсов}

По мере развития науки и техники, а также усиления человеческих потребностей в разрешении внезапных кризисных ситуаций, дистанционное образование стало глобальной тенденцией. Это неизбежно приведет к совершенствованию всей системы создания ресурсной базы онлайн-обучения: всесторонние исследования и повышение качества онлайн-курсов, создание высококачественных MOOC по всем специальностям, особое внимание к разработке "золотых курсов".

\section{4 Реформирование учебных средств, тшательная подготовка учебных материалов}

Преподаватели могут использовать задачно-ориентированный метод в сочетании с веб-трансляцией, проводить флип обучение (flipped classroom) и реструктуризацию учебного процесса, в результате чего будет формироваться совершенно новый гибридный режим занятий такой, как "онлайн+флип-класс". То есть, выбирая тематическое преподавание, преподаватели могут разделить занятия на три модуля: "предкласс+внутрикл асс+послекласс".

1. Предкласс: Преподаватели отбирают вопросы, интересующие студентов, а затем подготавливают подходящие MOOC, аудио-визуальные ресурсы, РРТ и электронную литературу и т.д. Вслед за этим, загружают данные учебные материалы на онлайнплатформу и там же сообщают тему, цели и задачи определенной главы. Следуя заданию, студенты самостоятельно изучают предоставленные преподавателем материалы для работы перед занятиями.

2. В классе: Преподаватели читают лекции через трансляцию, сосредоточивая внимание на ключевых и трудных вопросы. В реальной аудитории занятия обычно длятся 90 минут, однако время трансляции лучше всего ограничить 40 минутами, чтобы не заставлять студентов чувствовать зрительную и нервную усталость от долгого нахождения перед монитором. Остаток занятия можно перевести в режим флип-класса, чтобы студенты могли самостоятельно контролировать ход течения урока, а преподаватель лишь играл вспомогательную роль. Флип-класс включает в себя такие методы, как анализ кейсов, обсуждение и дебаты, проектные исследования, презентации, визиты репортеров, комментарии гидов, пение песен, дубляж фильмов, видеоклипы, рассказы и оценки студентов (студенты сами рассказывают и сами оценивают), вопросы и ответы студентов (студенты сами задают вопросы и сами отвечают на них), параллельное взаимодействие и более 10 других видов деятельности.

3. Послекласс: После занятий преподаватели и студенты вместе размышляют над содержанием изученного с целью улучшения его понимания. Студенты могут отвечать на вопросы, выполнять контрольные работы и тесты на образовательных порталах или загружать на них аудио-визуальные материалы, описание своих чувств, оценки, размышления и предложения, способствующие гармоничному взаимодействию преподавателей и студентов, а также постоянному совершенствованию занятий.

В процессе реализации флип обучения преподаватели могут свободно сочетать разные методы в соответствии со временем, местом, содержанием учебной программы, характеристиками учащихся и т.д., а не ограничиваться одним определенным учебным средством или платформой. То есть, “в специфической пе- 
дагогической среде непрерывно осуществлять инновации и совершенствование".[8, с.64] Для примера можно взять предмет «русская литература»: перед занятиями студенты могут читать обозначенные преподавателем произведения на сайте или в программе и писать свои впечатления о них; на занятиях проводится обмен впечатлениями о произведениях русской классической литературы, в рамках которого студенты делятся своими впечатлениями, обмениваются мнениями друг с другом, задают вопросы и вместе находят ответы с помощью преподавателя; после занятий студенты могут продолжить обсуждение на онлайн-платформе, например, загрузить свои сочинения на сайт или поделиться вопросами и обменяться найденными материалами.

Такой подход позволит не только превратить монотонную веб-трансляцию в активный семинар, но и усилить мотивацию студентов на занятиях, облегчить им доступ к материалам, и, в итоге, действительно достичь цели взаимодействия преподавания и обучения.

\section{Зак^ючение}

В целом, на фоне эпидемии коронавируса попытку масштабного дистанционного обучения в китайских университетах можно считать успехом, признанным большинством преподавателей и студентов. Во-первых, благодаря использованию онлайн-ресурсов "обучение больше не ограничено временем и местом" [9, с.188].
Таким образом, это помогло эффективно осуществить домашний карантин и предотвратить распространение заболеваний. Во-вторых, дистанционное обучение не только помогло защитить жизни и здоровье преподавателей и студентов, но и способствовало выполнению учебной задачи и достижения цели "отмена занятий, не означает отмену обучения". В-третьих, большое количество общедоступных высококачественных сетевых ресурсов дало студентам возможность в полной мере воспользоваться равенством образовательных ресурсов, тем самым реализовав идею о "хороших университетах без стен". Кроме того, новый способ обучения может значительно улучшить способности преподавателей и студентов по использованию передовых достижений науки и техники, владению и поиску актуальной информации и оказать помощь в подготовке талантов нового типа, соответствующих требованиям новой эпохи.

Если рассматривать данный вопрос глобально, можно сделать вывод, что существует тенденция к тому, чтобы дистанционное образование стало одним из основных способов обучения в будущем. В настоящее время из-за того, что мировая эпидемия все еще носит серьезный характер, дистанционное обучение по-прежнему широко используется в качестве эффективного средства, сдерживающего распространение эпидемии. Таким образом, попытка Китая, полученный опыт и возникшие проблемы, имеет референтное значение для дистанционного обучения в других странах.

\section{ЛИТЕРАТУРА}

1. Министерство образования Китая. “Отмена занятий, не означает отмену обучения" с использованием сетевой платформы[N]. Новости 0бразования Китая, 2020-02-01, С. 1.

2. Министерство образования Китая. "Советы по организации и управлению дистанционным обучением в колледжах и вузах при эпидемии COVID-19 ", [EB/OL]. (2020-02-05)

3. https://www.sohu.com/a/395155759_260616

4. Чжэн Вэнь, Чжан Юнбо, Лян Чуньхой. Исследование и практика дистанционного обучения во время эпидемии[Ј]. Журнал Чанчуньского инженерного колледжа (издание по социальным наукам), 2020, том. 21, № 2. С. 22.

5. Статистический бюллетень по отрасли связи 2020 года https://www.miit.gov.cn/gxsj/tjfx/txy/art/2021/art_057a331667154aaaa6767018dfd79a4f.html

6. Чжан Сяоцин, Ян Цзин. Разведка и практика дистационного обучения учащихся колледжов в отдаленных районах в период профилактики эпидемии и контроля - на пример дистационного обучения по специальности бизнес в коллежах провинции Синьцзян[J]. Вестник Синтайского профессиональнотехнического колледжа. 2020, том. 37, вып. 2, С. 2.

7. Чэнь Пин. Исследование о способах улучшения эффекта онлайн-обучения во время короновируса [J]. Вестник Хэйлунцзянского педагогического института. Март 2020. Том. 39, №. 5. С. 15.

8. Лю Чэнгун. Размышления об углубленном продвижении “идеологическое воспитание в профессиональные курсы” в колледжах и университетах[J]. Идеологическое и теоретическое образование. 2018, № 6, С. 64.

9. Сюэ Ли, Лин Цзянчуань. Размышления над эффективными стратегиям во время “Непрерывного обучения при приостановки классных занятий” [J]. Китайская мультимедиа и дистанционное образование (середина выпуска). 2020. (03). С. 188. 